\title{
InVESTigaÇão do TeOr de Nitrito em Linguiças do Tipo Toscana, Comercializadas na Região de Franca-SP
}

Dayana Cristina de Paula* Jacqueline Roberta Frutuozo* Thatiane Danielly Santos* Ana Lúcia Bassi Pinheiro**

\section{RESUMO}

Os sais de nitrito e nitrato em excesso são prejudiciais à saúde. O presente trabalho teve como objetivo avaliar a qualidade das linguiças do tipo toscana de vários fabricantes comercializadas na região de Franca-SP, por meio do método analítico quantitativo por espectrofotometria. Em paralelo, realizou-se uma avaliação do nível de conhecimento dos fabricantes sobre os riscos quanto ao uso abusivo desse aditivo. Os níveis de nitrito foram analisados em seis amostras de linguiça toscana, classificadas numericamente em: I, II, III, IV, V e VI, coletadas em supermercados distintos. O método foi baseado na reação do nitrito com o ácido sulfanílico e $\alpha$ naftol com formação de um azo composto. Constatou-se que as amostras I, II e III apresentaram concentração de nitrito muito superior ao permitido pela legislação $(150 \mathrm{mg} / \mathrm{kg})$. O questionário aplicado a três dos seis fabricantes revelou que dois deles desconhecem a legislação e não fazem análise da concentração do nitrito; somente um fabricante declarou não saber dos malefícios que esse aditivo poderia causar se usado indiscriminadamente. Os resultados permitiram indicar que 50\% das amostras estavam em desacordo com a legislação, portanto, medidas preventivas devem continuar sendo tomadas, como o controle de qualidade pelas indústrias e pela vigilância sanitária.

Palavras-chave: Nitrito; Linguiça; Aditivos; Produtos cárneos; Legislação.

\footnotetext{
*Graduandas do curso de Nutrição da Universidade de Franca.

**Professor-orientador da Universidade de Franca. Doutora em Química.

Endereço para contato: Rua: Gasparino de Andrade, n. ${ }^{\circ}$ 770. Bairro: Centro. Itaú de Minas-MG. E-mail: thatiane239@hotmail.com.
} 


\section{INTRODUÇ̃̃̃o}

As carnes são alimentos perecíveis e apresentam vida de prateleira variável em função das condições de armazenamento. Desde a Antiguidade, o homem sempre buscou preservar suas características de qualidade dos alimentos, originando-se, assim, processos e tecnologias de transformação, inicialmente rudimentares e atualmente controláveis por padrões tecnológicos para manter a qualidade dos produtos (OLIVEIRA; ARAÚJO; BORGO, 2005). Para aumentar a vida de prateleira desses produtos se utilizam aditivos alimentares.

A Portaria n. ${ }^{\circ}$ 540, de 27 de outubro de 1997, define aditivo alimentar como qualquer ingrediente adicionado intencionalmente aos alimentos, sem propósito de nutrir, com o objetivo de modificar as características físicas, químicas, biológicas ou sensoriais, durante a fabricação, processamento, preparação, tratamento, embalagem, acondicionamento, armazenamento, transporte ou manipulação. Essa definição não se refere aos contaminantes e não inclui substâncias nutritivas que sejam incorporadas ao alimento para manter ou melhorar suas propriedades nutricionais (ANVISA, 1997).

O mercado de embutidos tem apresentado significativa expansão e alta competitividade na última década, uma vez que o consumo de produtos cárneos, como salsichas, linguiças, mortadelas, hambúrgueres e outros, se tornou parte do hábito alimentar de uma parcela considerável de consumidores brasileiros. O preço acessível de algumas marcas, a praticidade do preparo e o valor proteico desses produtos contribuem para a redução do déficit nutricional, principalmente da população de menor renda. Todavia, convém considerar a forma de fabricação dos mesmos, e também a comercialização de embutidos de marcas desconhecidas, elaborados artesanalmente, sem qualquer fiscalização, pois expõem os consumidores aos riscos inerentes à ingestão de alimentos processados em condições precárias, ressaltando-se os relacionados aos aditivos empregados (MELO FILHO; BISCONTINI; ANDRADE, 2004).

As linguiças, em geral, são produtos comestíveis elaborados com diferentes carnes de animais de açougue, adicionados de ingredientes de cura ou não, submetidos a variados processamentos tecnológicos e embutidos com tripas naturais ou artificiais, sendo comercializadas em grande escala, por se tratar de um produto de valor comercial acessível a todos os setores da sociedade (LIRA et al., 2003). Entre os ingredientes de cura mais utilizados na fabricação de linguiças estão os sais de nitrato e nitrito.

Os nitratos e nitritos também podem estar presentes naturalmente em alimentos, e adicionados intencionalmente aos mesmos como conservadores. Evitam principalmente o desenvolvimento de esporos de Clostridium botulinum, cuja toxina causa o botulismo, além de conferirem sabor, aroma e cor avermelhada desejável em produtos cárneos curados. Embora o emprego de nitrito em processos de cura não seja recente, somente nos últimos anos a sua presença emalimentos tem despertado maior interesse 
na comunidade científica (TOLEDO; REYES, 1990). Esse interesse é decorrente de fatores de riscos toxicológicos que esses conservantes podem acarretar à saúde humana, dependendo da quantidade ingerida e suscetibilidade do organismo.

$\mathrm{O}$ nitrito ingerido em excesso pode agir sobre a hemoglobina e originar a mhemoglobinemia, impedindo que ela exerça a função normal de transportar oxigênio. A reação do íon nitrito comaminas e amidas presentes no meio pode dar origem às nitrosaminas e nitrosamidas, substâncias consideradas carcinogênicas, mutagênicas e teratogênicas (MELO FILHO, BISCONTINI; ANDRADE, 2004).

Alguns pesquisadores estimam que o consumo de produtos cárneos curados contribui com $25 \%$ a $30 \%$ do nitrito ingerido pela população (SILVA, 1999). Admitese que os aditivos permitidos, no âmbito internacional, quando utilizados nas concentrações corretas, não causam problemas à saúde humana (OLIVEIRA, ARAÚJO, BORGO, 2005).

Visando controlar o nível desses aditivos em produtos cárneos, a legislação brasileira estabeleceu o limite de teor residual de nitrito de $0,015 \mathrm{~g}$ por $100 \mathrm{~g}$ de produto cárneo, e de nitrato 0,03g por 100g (MINISTÉRIODAAGRICULTURA, 2007).

A proposta do presente trabalho foi avaliar a qualidade das linguiças do tipo toscana de vários fabricantes, comercializadas na região de Franca, por meio do método analítico quantitativo, determinando o teor de nitrito de sódio presente nas amostras analisadas, detectando os níveis de segurança alimentar para o consumidor, e também avaliar o nível de conhecimento dos fabricantes da região sobre os riscos quanto ao uso abusivo desse conservante.

\section{REVISÃO DA LITERATURA}

\subsection{Nitritos e nitratos}

Na natureza, os íons nitrato e nitrito são formados por meio de um processo de oxidação biológica (nitrificação), a partir do íon amônio, através de várias reações. Estas reações são mediadas por microrganismos do solo, como as nitrosaminas que oxidam o íon amônio a nitrito, realizando a primeira etapa da reação -, e as nitrobactérias - que oxidam o nitrito a nitrato, tornando este último mais abundante no ambiente. Nitritos e nitratos estão assim presentes no solo, na água e nos vegetais e, portanto, distribuídos naturalmente em alimentos de origem vegetal e animal (PURVES et al., 2001 apud ANDRADE, 2004).

Nitratos e nitritos são também utilizados como aditivos na forma de seus sais de sódio ou de potássio em produtos cárneos e em queijos (ANDRADE, 2004). Os sais de nitrito, além de conservarem a carne contra a deterioração bacteriana, são agentes de cura e fixadores da cor rósea avermelhada, característica dos produtos curados (OLIVEIRA; ARAÚJO; BORGO, 2005). A cor de um produto cárneo está associada 
à conformação química e à concentração dos pigmentos heme, mais especificamente da mioglobina, que é composta por uma cadeia polipeptídica denominada globina, acoplada a um grupo prostético, denominado heme. Este é constituído por umátomo de ferro e um anel porfirínico (CLYDESDALE; FRANCIS, 1976 apudANDRADE, 2004).

Alimentos à base de carne bovina têm sido relatados como um dos principais alimentos causadores de intoxicação alimentar. Acarne pode ser contaminada durante o abate, pelos microrganismos do próprio animal, pelo manipulador ou ainda pela poeira do meio ambiente (AMIN, 2005).

Segundo Amin e Oliveira (2006), o nitrito tem efeito antimicrobiano contra o Clostridium botulinum e também se mostra eficaz em relação a outros clostrídios, como o patogênico Clostridium perfringens. Amin (2005) afirma que a contaminação por Clostridium perfrigens tipo A pode levar a uma intoxicação alimentar que acarreta uma gastroenterite com os seguintes sintomas: dor abdominal aguda, diarreia intensa, febre e náuseas.

Para Manhoso e Rudge (1999 apud AMIN, 2005), a principal justificativa para o emprego do nitrito na elaboração de produtos cárneos se baseia no fato de prevenir o aparecimento de formas vegetativas e impedir a germinação e a multiplicação dos esporos de Clostridium sp. Jay (1994 apud AMIN, 2005); Franco e Landgraf(1996 apud AMIN, 2005) afirmam que o nitrito inibe os clostrídios ao interferir com enzimas que apresentam ferro e enxofre em sua estrutura, impedindo desse modo a síntese de adenosina trifosfato (ATP) a partir do piruvato. Essas enzimas atuam sobre o transporte de elétrons, originando ATP, hidrogênio e oxigênio.

Segundo Pinto (1998 apud LIRA et al., 2003), os níveis necessários de nitrito de sódio para a ocorrência dos seguintes efeitos em produtos cárneos são: 30 a $50 \mathrm{mg} / \mathrm{kg}$ para o desenvolvimento de cor, 20 a $40 \mathrm{mg} / \mathrm{kg}$ para o desenvolvimento de aroma, $80 \mathrm{a}$ $150 \mathrm{mg} / \mathrm{kg}$ para o efeito conservante e nível indeterminado para efeito antioxidante.

\subsection{Aspectos toxicológicos}

A aplicação dos sais nitrato e nitrito acima do limite máximo estabelecido pela legislação vigente pode acarretar sérios riscos à saúde humana, pela possibilidade de manifestações de efeitos tóxicos agudos e crônicos (MELO FILHO; BISCONTINI; ANDRADE, 2004). Os maiores riscos toxicológicos decorrentes da ingestão de nitratos e nitritos são a ocorrência de m-hemoglobinemia e a formação de compostos N-nitrosos (WALTERS, 1992 apud ANDRADE, 2004).

Os nitratos representam grave problema para a segurança alimentar, principalmente porque podem transformar-se em nitritos, quer durante a conservação dos alimentos entre a colheita e o consumo, quer dentro do aparelho digestivo (UFRGS, 2008). Segundo Andrade (2004), o nitrato pode ser reduzido a nitrito na cavidade oral, e a 
faixa ótima de $\mathrm{pH}$ para formação de nitrosaminas é semelhante àquela encontrada no estômago do homem após a ingestão de alimentos.

A possível síntese de nitrosaminas cancerígenas a partir de nitritos (provenientes, por exemplo, de pesticidas) e de diversas aminas representa grande preocupação. A ingestão de altas doses de nitratos e nitritos pode causar câncer do estômago e do esôfago. Acredita-se que quantidades muito pequenas de nitrosaminas possam se formar em determinados produtos cárneos curados. Esses níveis são na faixa de partes por milhão (ppm), sendo os procedimentos analíticos difíceis de serem executados com exatidão. Até o momento não existe um quadro claro dessa ocorrência de nitrosaminas, que podem ser voláteis ou não, e somente essas últimas são inclusas na análise de alimentos (UFRGS, 2008).

Britto (1997) mostra em seu trabalho sobre câncer de estômago (CE) que o nitrito pode ser um fator de risco. Mais recentemente, começou a ser reconhecido o potencial carcinogênico das nitrosaminas e nitrosamidas, genericamente chamadas de N-compostos (NOC) ou compostos N-nitrosos, substâncias formadas com a interação entre um grupo de nitrogênio secundário (que pode ser uma amina ou amida, uma alquil-ureia ou um anel peptídeo) e um nitrito. A evidência de que as populações de maior risco para o $\mathrm{CE}$ apresentavam dietas ricas em substratos para o processo de produção endógena de NOC desencadeou o interesse na avaliação dessas substâncias na gênese do CE. Esses compostos estão associados a mutações das células gástricas já alteradas pela gastrite atrófica crônica.

O nitrito também é mais tóxico que o nitrato por produzir, principalmente, vasodilatação e relaxamento da musculatura lisa em geral, além da formação de $m$ hemoglobina (OLIVEIRA; ARAÚJO; BORGO, 2005) impedindo que a hemoglobina exerça a função normal de transportar oxigênio (MELO FILHO; BISCONTINI; ANDRADE, 2004).

A dose letal para adultos está em torno de um grama (1g) de nitrito. Em doses mais baixas, os sintomas são enrubescimento da face e extremidades, desconforto gastrointestinal e dor de cabeça. Em doses tóxicas, um pouco mais elevadas, observam-se cianose, náusea, vômitos, dores abdominais e colapso (OLIVEIRA; ARAÚJO; BORGO, 2005).

O nitrato ingerido nos alimentos pode ser reduzido a nitrito $\left(\mathrm{NO}_{2}^{-}\right)$no trato digestivo, e ao chegar à corrente sanguínea oxida o ferro $\left(\mathrm{Fe}^{2+} \mathrm{aFe}{ }^{3+}\right)$ da hemoglobina, produzindo $m$-hemoglobina. Esta se torna estável e inativa, incapaz de transportar oxigênio $\left(\mathrm{O}_{2}\right)$ para a respiração celular, o que leva à doença conhecida como $m$-hemoglobinemia, ou doença do "sangue azul" (MATIAS; COMETTI; FERNANDES, 1999). Quando os níveis de exposição ao nitrito são baixos, a formação de $m$-hemoglobina é reversível; quando elevados, o sistema de redução é saturado, resultando em um aumento da 
concentração de $m$-hemoglobina no sangue. Este processo está representado na Figura 1. Níveis de $m$-hemoglobina de $10 \%$ podem produzir cianose assintomática, e com níveis entre 20 e $30 \%$ há o aparecimento de cianose com sinais de hipoxia, astenia, dispneia, cefaleia, taquicardia e inconsciência. Concentrações em níveis superiores a $50 \%$ podem ser fatais (BORONAT et al., 1982 apud ANDRADE, 2004).

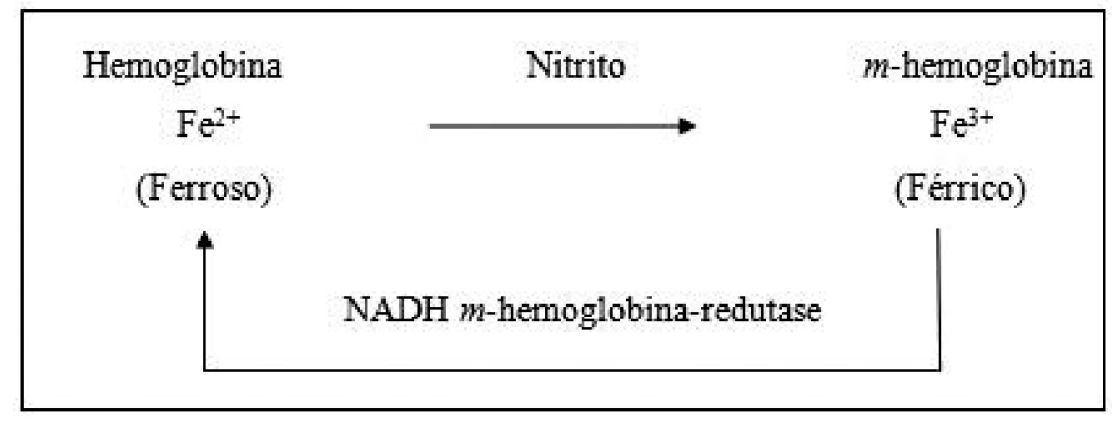

Figura 1. Formação de $m$-hemoglobina pelo nitrito e sua conversão à hemoglobina. Fonte: SWANN, 1975 apud ANDRADE, 2004.

Embora a $m$-hemoglobinemia seja a princípio o mais ameaçador efeito da exposição ao nitrato, várias pesquisas sobre a alta exposição do mesmo têm sido ligados a uma variedade de efeitos, como hipertrofia, aumento da tireoide, hipertensão e até efeitos carcinogênicos, devido à formação de compostos $\mathrm{N}$-nitrosos. Todos os efeitos têm sido observados em estudos epidemiológicos em seres humanos, e são frequentemente sustentados por estudos de fisiologia humana e animal (BRUNING-FANN; KANEENE, 1993 apud ANDRADE, 2004).

\subsection{Inibidores daformação de nitrosação}

As reações de nitrosação, por sua vez, podem ser inibidas por neutralização do nitrito com substâncias de ocorrência natural ou sintética presentes nos alimentos, tais como as vitaminas C e E. Segundo Fan e Tannenbaum (1973 apudANDRADE, 2004), outras substâncias podem ser catalisadoras da reação de nitrosação, tais como tiocianato, formaldeído, ácidos e haletos; e como inibidores, ascorbato, $\alpha$ tocoferol e dióxido de enxofre.

Segundo Scanlan (1983 apudANDRADE, 2004)e Potter(1996 apud ANDRADE, 2004), nos alimentos podem existir substâncias inibidoras da reação de formação de nitrosaminas, tais como: taninos, compostos fenólicose vitaminas C, EeA. Particularmente, o ácido ascórbico e o $\alpha$-tocoferol são, provavelmente, os inibidores mais importantes, uma vez que se encontram naturalmente presentes emalguns alimentos.

A ação inibidora do ácido ascórbico sobre a reação de nitrosação de uma amina 
foi descoberta acidentalmente na formulação do analgésico aminopirina, quando foi inibida a formação de nitrosodimetilamina. Posteriormente, foi observado que esta vitamina inibia fortemente a formação de compostos $\mathrm{N}$-nitrosos a partir da maioria das aminas e amidas (MIRVISH, 1972 apud ANDRADE, 2004). Em consequência, a administração conjunta de ácido ascórbico (ou carotenóides) e aminas (ou amidas) em animais inibe os efeitos hepatotóxicos, carcinogênicos e teratogênicos provenientes da síntese endógena de nitrosaminas ou nitrosamidas (WALTERS, 1992; ATANASOVA-GORANOVA, 1997 apud ANDRADE, 2004).

Portanto, a importância da contribuição dos nitratos para o desenvolvimento de câncer de localização gástrica parece depender desse complexo balanço de influências facilitadoras e inibitórias na formação in situ de compostos N-nitrosos genotóxicos, e do tempo de exposição a esse fator de risco (GOMES-CARNEIRO; RIBEIRO-PINTO; PAUMGARTTEEN, 1997).

\subsection{Aspectos de legislação}

$\mathrm{O}$ limite tolerado de nitrito e nitrato como aditivo alimentar depende, em particular, do produto alimentício e da legislação vigente de cada país.

O uso de aditivos é regulamentado no mundo através do Codex Alimentarius Comission (Comissão de Código Alimentar) com sede em Genebra. O Codex é, em suma, uma coletânea de padrões para alimentos destinados à aplicação internacional e com apresentações uniformes (TURRA, 1998).

No Brasil, a Agência Nacional de Vigilância Sanitária (Anvisa) determina os limites desses aditivos em carnes e produtos cárneos, conforme a Tabela 1:

Tabela 1. Concentração Máxima de Aditivos em Carnes e Produtos Cárneos

\begin{tabular}{cc}
\hline Aditivos & Concentração Máxima $\mathbf{g} / \mathbf{1 0 0 g}$ \\
Nitrito de potássio & 0,015 \\
Nitrito de sódio & 0,015 \\
Nitrato de sódio & 0,03 \\
Nitrato de potássio & 0,03 \\
\hline
\end{tabular}

Fonte: Ministério da Agricultura, 2007.

\section{Metodologia}

\subsection{Material}

As soluções utilizadas neste experimento foram: solução I: Bórax ou Tetraborato de Sódio ( $\left.\mathrm{Na}_{2} \mathrm{~B} 4 \mathrm{O} 7.10 \mathrm{H}_{2} \mathrm{O}\right)$; solução II: Ferrocianeto de Potássio $\left(\mathrm{K}_{4}[\mathrm{Fe}(\mathrm{CN})]\right.$ ); solução III: Acetato de Zinco ( $\left.\mathrm{CH}_{3} \mathrm{COO}\right)_{2} \mathrm{Zn}$. 2 $\left.\mathrm{H}_{2} \mathrm{O}\right)$; solução IV: Ácido Acético $\left(\mathrm{CH}_{3} \mathrm{COOH}\right)$; solução Tampão $\mathrm{pH}=9,65$; solução $\alpha$-naftol $\left(\mathrm{C}_{10} \mathrm{H}_{8} \mathrm{O}\right.$, reagente cromogênico); solução 
branco (reagente); e solução de ácido clorídrico (HCl) 0,1 N.

Para o preparo as soluções foram utilizados: Nitrato de Sódio P.A., marca: Cinética; Tetraborato de Sódio P.A. Decahidratado (Bórax), marca: Vetec; Potássio Ferrocianeto P.A.-ACS, marca: Ecibra; $\alpha$-Naftol 134, marca: Vetec; Acetato de Zinco, marca: Audaz; Ácido Clorídrico P. A., marca: Vetec; Hidróxido de Amônio P.A. - ACS, marca: Synth; Ácido Acético Glacial P.A., marca: Cromoline.

As análises foramfeitas usando um espectrofotômetro da Fento, modelo 600.

$\mathrm{O}$ aquecimento das amostras foi realizado utilizando-se um sistema de banhomaria com temperatura controlável, da marca Fanem modelo 100.

Para a realização das pesagens utilizou-se uma balança analítica da marca Marte.

\subsection{Métodos}

Para a avaliação do conhecimento dos fabricantes sobre os riscos quanto ao uso abusivo desse conservante, foi aplicado um questionário, com as seguintes questões:

1 -A concentração está dentro dos padrões da legislação vigente?

2 - São realizadas análises de concentração desses conservantes?

3 - Quais são os efeitos toxicológicos, e o que estes acarretam à saúde?

4 -Qual a finalidade do uso do nitrito e nitrato no produto?

5 -No momento em que se adiciona o conservante no produto, este já pode ser consumido?

O método utilizado neste trabalho para a determinação de nitrito foi descrito por Ximenes, Rodrigues e Marques (1998), e está descrito a seguir.

\subsubsection{Preparo da solução de Bórax ou Tetraborato de sódio $\left(\mathrm{Na}_{2} \mathrm{~B}_{4} \mathrm{O}_{7}\right.$. 10H 2 O)}

Utilizando uma balança analítica, foram pesados em um becker $25 \mathrm{~g}$ de bórax, em seguida transferidos para um balão volumétrico de $500 \mathrm{ml}$ e dissolvidos em água destilada.

\subsubsection{Preparo da solução de Ferrocianeto de Potássio $\left(\mathrm{K}_{4}\left[\mathrm{Fe}(\mathrm{CN})_{6}\right]\right)$}

Utilizando uma balança analítica, pesaram-se em um becker $53 \mathrm{~g}$ de Ferrocianeto de Potássio, em seguida transferidos para um balão volumétrico de $500 \mathrm{~mL}$ e dissolvidos em água destilada.

\subsubsection{Preparo da solução de Acetato de $\mathrm{Zinco}\left(\mathrm{CH}_{3} \mathrm{COO}\right)_{2} \mathrm{Zn}$. 2 $\left.\mathrm{H}_{2} \mathrm{O}\right)$}

Utilizando uma balança analítica, foram pesados em um becker $110 \mathrm{~g}$ de acetato de zinco, em seguida transferidos para um balão volumétrico de $500 \mathrm{~mL}$ e dissolvidos em água destilada. 


\subsubsection{Preparo da solução de Ácido Acético $\left(\mathrm{CH}_{3} \mathrm{COOH}\right)$}

Utilizando uma pipeta, transferiram-se $15 \mathrm{ml}$ de ácido acético para um balão volumétrico de $500 \mathrm{~mL}$, completados com água destilada.

\subsubsection{Preparo da solução de ácido clorídrico (HCl 0,1N)}

Para o preparo da solução de $0,1 \mathrm{~N}$ de $\mathrm{HCl}$, foram dissolvidos $3,65 \mathrm{~g}$ de $\mathrm{HCl} \mathrm{em}$ $1 \mathrm{~L}$ de água.

Sabendo que o HCl utilizado é concentrado, a sua densidade é de $1,18 \mathrm{~g} / \mathrm{mL}$ e a sua concentração é de $37 \%$, o volume necessário para diluí-lo foi de $9,8 \mathrm{~mL}$ de $\mathrm{HCl}$ concentrado para $1 \mathrm{~L}$ de água.

\subsubsection{Preparo da solução tampão $(\mathrm{pH}=9,65)$}

Para o preparo da solução tampão, foram utilizados $40 \mathrm{ml}$ de $\mathrm{HCl}$ concentrado mais $100 \mathrm{ml}$ de $\mathrm{NH}_{4} \mathrm{OH}$ concentrado, completados com água destilada (balão volumétrico de $1000 \mathrm{ml}$ ). Acertou-se o $\mathrm{pH}$ com NH $\mathrm{NH}_{4} \mathrm{OH} \%$.

\subsubsection{Preparo da solução de $\alpha$-naftol $\left(\mathrm{C}_{10} \mathrm{H}_{8} \mathrm{O}\right)$}

Para o preparo da solução de $\alpha$-naftol (reagente cromogênico), aqueceram-se $180 \mathrm{ml}$ de água destilada com $25 \mathrm{ml}$ de ácido acético glacial concentrado a $50^{\circ} \mathrm{C}$. Foram diluídos $125 \mathrm{mg}$ de ácido sulfanílico e, em seguida, $100 \mathrm{mg}$ de $\alpha$-naftol. Esfriou-se a solução à temperatura ambiente e então foram adicionados $90 \mathrm{ml}$ de $\mathrm{NH}_{4} \mathrm{OH} 10 \%$. O pH desta solução variou de 4,0 - 4,5.

\subsubsection{Solução branco (reagente)}

Para o preparo da solução branco, adicionaram-se $10 \mathrm{ml}$ de $\alpha$-naftol com $10 \mathrm{ml}$ de água destilada. A esta solução foram acrescentados $5 \mathrm{ml}$ da solução tampão.

\subsubsection{Solução padrão de reagente Nitrito $\left(\mathrm{NaNO}_{2}\right)$}

Para o preparo da solução padrão de reagente nitrito, pesou-se $0,5 \mathrm{~g}$ de $\mathrm{NaNO}_{2}$, transferido para o balão volumétrico de $1000 \mathrm{ml}$ com água destilada.

\subsection{Método de varredura}

Inicialmente foi realizada uma varredura espectrofotométrica na região do ultravioleta visível (UV-Vis) para confirmação do comprimento de onda $(\lambda)$ de melhor absorção para desenvolvimento do método, no intervalo de 350 a $720 \mathrm{~nm}$.

\subsection{Curva de calibração}

Alíquotas de 0,$1 ; 0,2 ; 0,4 ; 0,8$ e 1,6 ml da solução padrão de nitrito de sódio 
foram transferidas para um balão volumétrico de $100 \mathrm{ml}$. A esta solução se adicionaram $5 \mathrm{ml}$ de solução tampão ( $\mathrm{pH}$ 9,65), mais água destilada.

Num erlenmeyer foram postos $5 \mathrm{ml}$ de cada solução padrão, sendo acrescentados, posteriormente, $10 \mathrm{ml}$ do reagente cromogênico, $5 \mathrm{ml}$ de água destilada e $5 \mathrm{ml}$ de solução tampão. A solução branco utilizada foi descrita anteriormente.

Deixou-se em banho-maria a $30^{\circ} \mathrm{C}$ por 30 minutos. Após, leu-se a absorbância em $474 \mathrm{~nm}$ no espectrofotômetro.

\subsection{Desproteinização}

Pesaram-se $10 \mathrm{~g}$ de cada amostra de linguiça triturada e homogeneizada. Adicionaramse $5 \mathrm{ml}$ da solução Bórax e $40 \mathrm{ml}$ de água destilada, em cada uma dessas amostras, deixadas embanho-maria a $80^{\circ} \mathrm{C}$ por 15 minutos, agitando frequentemente. As amostras foram resfriadas à temperatura ambiente e, posteriormente, adicionadas a cada uma $2 \mathrm{ml}$ da solução II $\left(\mathrm{K}_{4}\left[\mathrm{Fe}(\mathrm{CN})_{6}\right]\right)$ e $2 \mathrm{ml}$ da solução III $\left.\left(\mathrm{CH}_{3} \mathrm{COO}\right)_{2} \mathrm{Zn}_{2} 2 \mathrm{H}_{2} \mathrm{O}\right)$, agitando-se vigorosamente após cada adição durante cinco minutos. Em seguida, foram transferidas para um balão volumétrico de $100 \mathrm{ml}$ e deixadas em repouso durante 30 minutos. Todas as amostras emanálise foram completadas, atéo volume de $100 \mathrm{ml}$, com água destilada, depois agitadas vigorosamente até a precipitação de um sólido laranja, conforme ilustrado na Figura 2, e posteriormente filtradas. Após esse processo se determinou-se a concentração de nitrito presente em cada amostra.

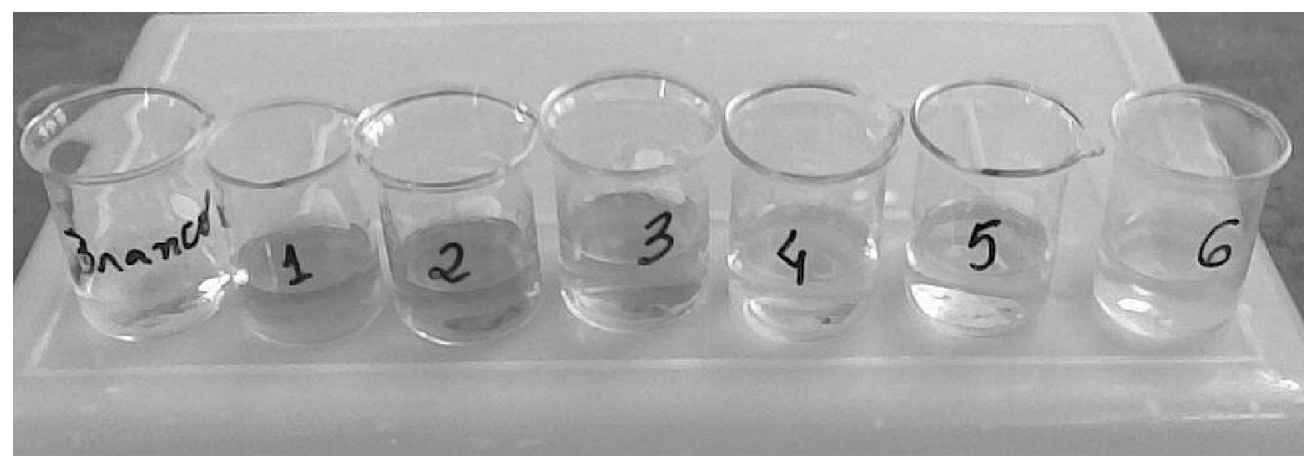

Figura 2. Coloração das amostras I - VI, após o processo de desproteinização.

\subsection{Determinação de nitrito}

Partiu-se de $10 \mathrm{ml}$ de cada amostra de linguiça desproteinizada. Adicionaramse $5 \mathrm{ml}$ de solução tampão e $10 \mathrm{ml}$ de $\alpha$-naftol (reagente cromogênico). Deixouse a solução em banho-maria durante 30 minutos a $30^{\circ} \mathrm{C}$. Após o resfriamento, foi realizada a leitura no espectrofotômetro a $474 \mathrm{~nm}$. Calculou-se o valor de nitrito presente nas amostras, usando a curva padrão previamente estabelecida. 


\section{ReSUltados E DISCUSSÃo}

A Tabela 2 reúne as respostas dos fabricantes II, V e VI ao questionário aplicado.

Tabela 2. Resultados do Questionário.

\begin{tabular}{cccc}
\hline Questões & Fabricante II & Fabricante V & Fabricante VI \\
1 & $\begin{array}{c}\text { Sim, porém desconhece } \\
\text { a legislação. }\end{array}$ & $\begin{array}{c}\text { Sim, de acordo com a } \\
\text { legislação é de 0,3\%/kg }\end{array}$ & $\begin{array}{c}\text { Não sabe. Utiliza a concentração } \\
\text { indicada na embalagem. }\end{array}$ \\
2 & Não. & $\begin{array}{c}\text { Sim, analisam de } 3 \mathrm{em} 3 \\
\text { meses. }\end{array}$ & $\begin{array}{c}\text { Não. Pois o produto já vem } \\
\text { pronto para o uso. }\end{array}$ \\
& Sim, é cancerígeno. & Sim, é cancerígeno. & $\begin{array}{c}\text { Nãonsa que faz mal, mas } \\
\text { não sabe o motivo. }\end{array}$ \\
4 & $\begin{array}{c}\text { Maior tempo de duração } \\
\text { do produto. }\end{array}$ & $\begin{array}{c}\text { Manter a vida útil do } \\
\text { produto. }\end{array}$ & Conservar. \\
5 & $\begin{array}{c}\text { Sim, mas sempre deixa } \\
\text { curando por 12 horas. }\end{array}$ & $\begin{array}{c}\text { Sim, porém o ideal é } \\
\text { deixar 12 horas } \\
\text { descansando. }\end{array}$ & $\begin{array}{c}\text { Sim, mas sempre deixa curando } \\
\text { por 12 horas. }\end{array}$ \\
\hline
\end{tabular}

Analisando o questionário, com relação à pergunta $\mathbf{1}$, apenas o fabricante $\mathbf{V}$ tinha conhecimento do limite de nitrito em porcentagem que poderia ser utilizado, porém não sabia o valor residual do mesmo exigido por lei, mas garantiu que está dentro do permitido. O fabricante II também confirmou a legalidade dos níveis utilizados no seu produto, mas desconhece quais são. Já o fabricante VI admitiu não saber se seu produto está dentro das normas legais em relação à quantidade de nitrito e se justifica, apenas, seguindo as recomendações especificadas nos rótulos. Com relação à questão $\mathbf{2}$, sobre a análise de concentração de nitrito nas linguiças, apenas o fabricante $\mathbf{V}$ realiza tal procedimento.

Quando questionados sobre como a utilização excessiva desse conservante poderia afetar a saúde humana, os fabricantes II e V mostraram o conhecimento em relação ao desenvolvimento do câncer, contrariando o fabricante VI, que disse não saber dos malefícios.

Na questão 4 os três foram unânimes ao responder que o uso se destinava à conservação do produto cárneo, assim como na questão $\mathbf{5}$, em que todos recomendaram o descanso de 12 horas do produto, para depois serem consumidos, mas que o consumo imediato também podia ser realizado.

\subsection{Determinação do nitrito}

Na região de Franca, seis das amostras de linguiça adquiridas em supermercados, em diferentes pontos de comercialização, foram submetidas aos ensaios analíticos, em duplicatas.

\subsection{Determinação da curva padrão}


Para que um método seja considerado linear é preciso que o seu coeficiente de correlação $\left(R^{2}\right)$ apresente um valor mínimo igual a 0,99 . O coeficiente de correlação indica o grau de correlação ou associação linear entre dois métodos (BASQUES, 2007).

A linearidade do método foi testada utilizando-se duplicatas de cinco alíquotas de 0,$1 ; 0,2 ; 0,4 ; 0,8 ;$ e $1,6 \mathrm{~mL}$ da solução padrão de nitrito de sódio $\left(\mathrm{NaNO}_{2}\right)$, como descrito na metodologia. Com os dados obtidos, foi confeccionado um gráfico de absorbância em função da concentração de $\mathrm{NaNO}_{2}$, conforme mostra a Figura 3 .

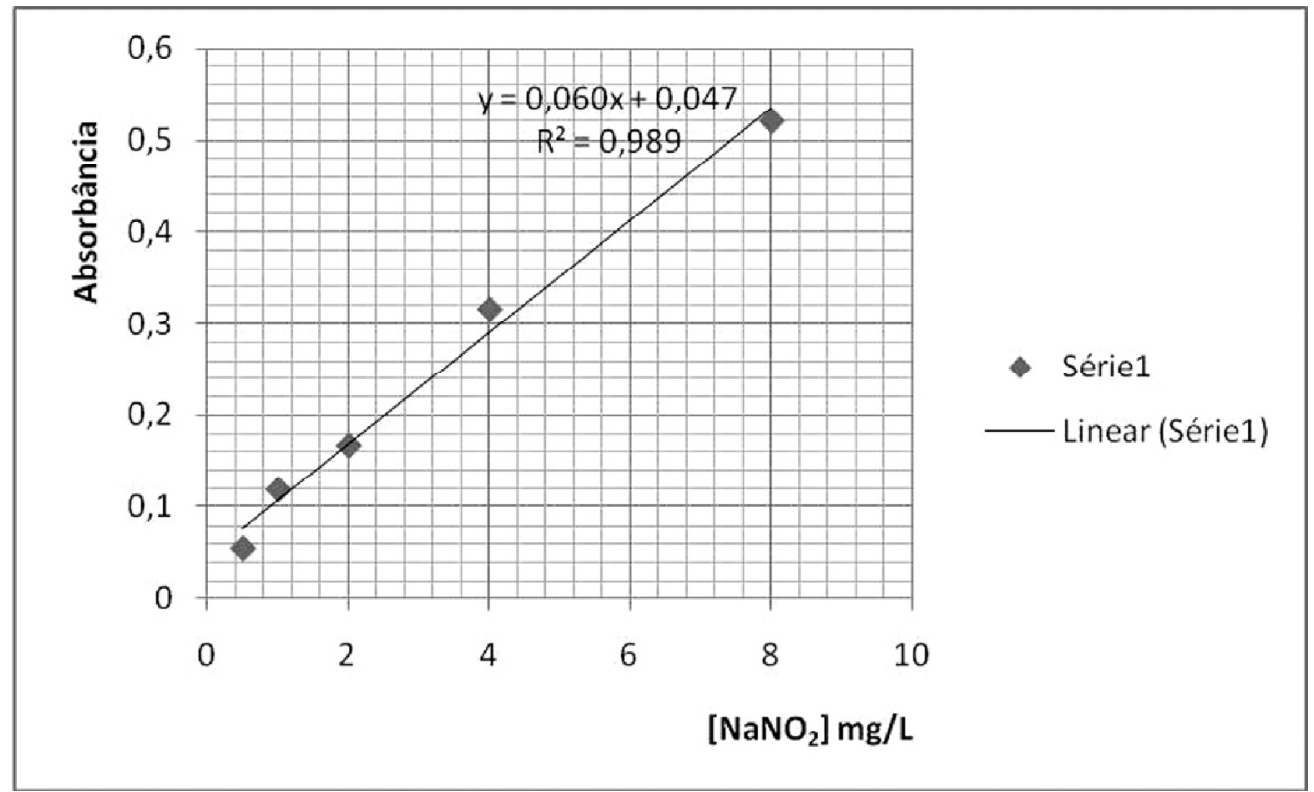

Figura 3. Gráfico de Absorbância em função da concentração de $\mathrm{NaNO} 2$, no intervalo entre $0,5-8,0 \mathrm{mg} / \mathrm{L}$.

Analisando o gráfico da Figura III, observou-se uma boa linearidade entre os pontos. Para tanto, calculou-se o coeficiente de correlação $\left(\mathrm{R}^{2}\right)$, o coeficiente angular (a) e a intersecção da reta no eixo y (b). Esses resultados se encontram na Tabela 3.

Tabela 3. Resultados obtidos por meio da regressão linear dos pontos de absorbância em função da concentração de $\mathrm{NaNO}_{2}(\mathrm{mg} / \mathrm{L})$.

\begin{tabular}{lc}
\hline \multicolumn{1}{c}{ Parâmetro } & Resultado \\
\hline Coeficiente de correlação $\left(\mathbf{R}^{2}\right)$ & 0,989 \\
Coeficiente angular (a) & 0,060 \\
Intersecção da reta no eixo y (b) & 0,047 \\
\hline
\end{tabular}


Esses dados mostram que o método é satisfatório, visto que o coeficiente de correlação obtido $(0,989)$ foi próximo do valor considerado como método linear $(0,99)$. A análise das diferenças entre os resultados encontrados e as concentrações esperadas foram suficientes para estabelecer a linearidade do método.

\subsection{Desproteinização}

Após as linguiças terem sido desproteinizadas, como descrito na metodologia, determinou-se a concentração de nitrito presente em cada amostra.

A técnica de espectrofotometria tem o objetivo de determinar a concentração de nitrito de sódio presente nas amostras de diferentes tipos fornecedores de lingüiça analisadas.

Valores médios de nitrito de sódio encontrados nas linguiças de vários fabricantes comercializadas na região de Franca estão explicitados estatisticamente, como mostra a Tabela 4:

Tabela 4. Nitrito de sódio $(\mathrm{mg} / \mathrm{Kg})$ em linguiças de vários fabricantes comercializadas na região de Franca.

\begin{tabular}{ccc}
\hline Amostras & Absorbância & $\mathbf{N a N O}_{\mathbf{2}} \mathbf{~ m g} / \mathbf{K g}$ \\
\hline I & 0,989 & 1.510 \\
II & 0,725 & 1.098 \\
III & 0,260 & 371 \\
IV & 0,010 & 0,0 \\
V & 0,016 & 0,0 \\
VI & 0,048 & 40 \\
\hline
\end{tabular}

Esses resultados demonstram que houve variação na concentração de nitrito de sódio (mg/Kg) nas amostras dos diferentes fabricantes de linguiça na região de Franca.

Uma diferença significativa nas amostras I, II e III mostrou uma alta concentração de nitrito de sódio presente, ultrapassando aproximadamente em dez, sete, e três vezes, respectivamente, a quantidade permitida pela legislação.

Ao analisarem-se as respostas do questionário realizado e os resultados obtidos com as amostras, verificou-se que uma das maiores concentrações de nitrito foi encontrada no produto originário do fabricante II, um dos que desconhecem a legislação, não fazem análises de seus produtos, mas têm conhecimento da gravidade efetiva que isso pode causar à saúde de seus consumidores.

Estudos mostraram que a diminuição da taxa de mortalidade por câncer gástrico (em dois terços) foi associada à redução de cerca de $75 \%$ na utilização de nitrato e nitrito na conservação de carnes, a partir de 1925 (ABREU, 1997). 
Na Região Metropolitana de São Paulo foram analisadas 45 amostras de linguiça do tipo frescal, e os valores encontrados demonstraram que o limite legal foi ultrapassado em 26,67\% das amostras (TAVARES et al., 1987 apud OLIVEIRA; ARAÚJO; BORGO, 2005).

Com relação às amostras $I V$ e $\mathbf{V}$, não se observou traço de nitrito pelo método analisado, sendo assim, não há ocorrência de nenhum efeito desejável no produto, como desenvolvimento da cor, do aroma e do efeito conservante.

O estudo realizado por Lira et al. (2003) na cidade de Maceió-AL, com intuito de analisar a concentração de nitrito em produtos cárneos provenientes de estabelecimentos comerciais, encontrou teores desse conservante abaixo do limite máximo residual permitido pela legislação brasileira - e do nível mínimo necessário para a ocorrência dos efeitos desejáveis para o produto -, em todas as amostras, inclusive a da linguiça toscana (0,5 a $1,6 \mathrm{mg} / \mathrm{kg})$.

Pinto et al. (1998 apud LIRA et al., 2003), ao avaliarem os teores de nitrito em linguiças caseiras comercializadas no município de Araçatuba-SP, observaram que, das 19 amostras analisadas, 15 não continham quantidade suficiente de nitrito para desenvolver nenhum efeito nos produtos, e que em 1 delas se notou um teor de nitrito acima do estabelecido pela legislação vigente, demonstrando a falta de orientação por parte dos fabricantes.

Somente a amostra VI apresentou uma quantidade que não ultrapassou os limites aceitáveis pela legislação brasileira que, como citado anteriormente, estabelece que o limite de teor residual de nitrito é de $0,015 \mathrm{~g}$ por $100 \mathrm{~g}(150 \mathrm{mg} / \mathrm{Kg})$ de produto cárneo. Porém, essa quantidade $(40 \mathrm{mg} / \mathrm{kg}$ ) é insuficiente para a conservação do produto, mas é suficiente para o desenvolvimento da cor e aroma do mesmo.

Segundo o Instituto Brasileiro de Defesa do Consumidor (Idec), em recente análise de 14 marcas de linguiças tipo toscana, todas obtiveram um resultado positivo em relação ao uso de nitrito, apresentando níveis que se encontravam dentro dos limites permitidos por lei.

\section{Conclusão}

Apesar de o nitrito ser utilizado há muito tempo, e de seus aspectos serem conhecidos por vários estudos realizados durante as últimas décadas, ainda existem falhas quanto ao seu uso e fiscalização, o que pode ser verificado nos resultados obtidos. Observou-se que três das seis amostras apresentaram inadequação muito significativa em relação aos valores recomendados pela legislação vigente, com altas taxas de concentração residual.

Em relação às demais amostras, os teores de nitrito não comprometem a saúde do consumidor, pois seus níveis estavam todos abaixo do limite máximo, porém 
insuficientes para a conservação do produto.

Com base nas respostas obtidas no questionário, foi observado que os conhecimentos dos fabricantes a respeito da finalidade desse conservante, assim como seus efeitos toxicológicos, são limitados. Desconhecem a respectiva legislação referente à utilização do composto e, consequentemente, as prováveis implicações na manipulação sem critérios do mesmo. A falta de fiscalização dos níveis de nitrito e de conhecimentos por parte dos fabricantes faz com que seu uso se torne indiscriminado. Cabe ao fabricante a responsabilidade sobre o produto e, portanto, este precisa se adequar às normas de segurança alimentar. Quanto aos procedimentos de eliminar, reduzir e/ou prevenir riscos à saúde, cabe à vigilância sanitária disseminar orientações sobre tais procedimentos a quem produz, além de realizar controle permanente do uso de nitrito na fabricação de produtos cárneos.

\section{REFERÊNCIAS}

ABREU, E. A prevenção primária e a detecção do câncer de estômago. Cad. Saúde Públ., Rio de Janeiro, v.13 (Supl. 1) p.105-108, 1997. Disponívelem: <http: //www.scielo .br/pdf/csp/ v13s1/ 143 1.pdf>. Acesso em: 25 abr. 2009.

\section{AMIN, M. Efeito do uso do nitrato e nitrito na inibição de Clostridium} perfringens tipo A em linguiiça bovina curada. 2005. Dissertação (Mestrado em Ciência Animal) Universidade Federal de Mato Grosso do Sul. Área de concentração: SaúdeAnimal. Disponível em: <http://www. cbc.ufms. br/tedesimplificado/tde_busca/ arquivo.php?codArquivo=82>. Acesso em: 9 jun. 2008.

AMIN, M.; OLIVEIRA, J. V. Efeito do uso do nitrato e nitrito na inibição de Clostridium perfringens tipo A em lingüiça bovina curada. B.CEPPA, Curitiba v. 24, n. 1, p. 13-24 jan./jun. 2006. Disponível em: <http://ojs. c3sl. ufpr. br/ ojs2/ index.php/alimentos/article/view/5303/5490>. Acesso em: 24 jun. 2008.

\section{ANDRADE, R. Desenvolvimento de métodos analíticos para determinação de} nitrato, nitrito e N-Nitrosaminas em produtos cárneos. 2004. Dissertação (Doutorado em Ciências) Universidade Estadual de Campinas,. Disponível em: <http:// biq.iqm.unicamp. br/ arquivos/teses/vtls000349194.pdf>. Acesso em: 4 jun. 2008

ANVISA - Agência Nacional de Vigilância Sanitária. Portaria no 540 - SVS/MS, de 27 de outubro de 1997. Disponível em: <http://www. anvisa. gov.br/ legis/ portarias/ 540_97. htm>.Acesso em: 28 abr. 2009. 
BASQUES, J. C. Validação quantitativa. In: CONGRESSO BRASILEIRO DE ANÁLISES CLÍCNICAS, 34. Belo Horizonte. Jun. 2007. Disponível em: <http:// www.labest.com.br>. Acesso em: 30 jun. 2008.

BRASIL. Ministério da Agricultura. Regulamento técnico de atribuição de aditivos, e seus limites das seguintes categorias de alimentos: carnes e produtos cárneos, 2007. Disponível em :

Hrrp:// extranet.agricultura.gov.br/sislegis-conmsulta/servlet/ visualizaranexo $?=14706>$. Acesso em:

15 fev. 2009.

BRITTO, A. V. Câncer de estômago: fatores de risco. Cad. Saúde Públ., Rio de Janeirov. 13 (Supl. 1):7-13, 1997. Disponível em: <http://www.scielo.br/pdf/csp/ v13s1/1421.pdf>. Acesso em: 4 jun. 2008.

GOMES-CARNEIRO, M. R.; RIBEIRO-PINTO, L. F; PAUMGARTTEEN, F. J. R. Fatores de risco ambientais para o câncer gástrico: a visão do toxicologista. Cad. Saúde Públ., Rio de Janeiro, 13 (Supl. 1), p.27-38, 1997. Disponível em: <http://www. scielosp. org/pdf/csp/v13s1/ 1423. pdf>. Acesso em: 9 jun. 2008.

IDEC - INSTITUTO DE DEFESA DO CONSUMIDOR. Lingüiça toscana: muita gordura, pouca proteína. Rev. ConsumidorS.A. Online, n. 51, jun./jul. 2000. Disponível em: < http://www.idec. org.br/consumidorsa/arquivo/jul00/index.htm>. Acesso em: 16 jun. 2009.

LIRA, G. M. et al. Teores de nitrito de sódio em produtos cárneos comercializados em Maceió. AL. Rev. Inst. Adolfo Lutz, v. 62, n. 3, p. 165-170, 2003.

\section{MATIAS, G. C. S.; COMETTI, N. N.; FERNANDES, M. S. Teor de nitrato} nas várias partes da alface. 1999. Disponível em: <http:// www.niltoncometti.hpg.com.br/Trabalhos_congressos/Teor_nitrat_alfac.pdf $>$. Acesso em: 6 jul. 2008.

MELO FILHO, A. B.; BISCONTINI, T. M. B.; ANDRADE, S. A C. Níveis de nitrito e nitrato em salsichas comercializadas na região metropolitana do Recife.

Ciênc. Tecnol. Aliment., Campinas, v.24,n.3,p.390-392, jul.-set. 2004.

Disponível em: 〈http://www.scielo.br/pdf/cta/v24n3/21931.pdf >. Acesso em: 14 jul. 2008. 
OLIVEIRA, M. J.; ARAÚJO, W. M. C.; BORGO, L. A. Quantificação de nitrato e nitrito em lingüiças do tipo frescal. Ciênc. Tecnol. Aliment., Campinas, v.25, n.4, p.736-742, out.-dez. 2005. Disponívelem: <http://www.scielo.br/pdf/cta/v25n4/ 27644. pdf>. Acesso em: 14 jul. 2008.

OLIVEIRA, M. J.; ARAÚJO, W. M. C.; BORGO, L. A. Riscos químicos em lingüiça do tipo frescal: aspectos teóricos. Revista Higiene Alimentar, v. 19, n. 130, p. 24-28, abr. 2005.

SILVA, J. A. Ocorrência e controle de Clostridium botulinum em produtos cárneos curados. Revista TeC Carnes, Campinas. 1, p. 44-56, 1999.

TOLEDO, M. C. F.; REYES, F. G. R. Nitratos e Nitritos: presença em alimentos e riscos de sua ingestão. R. Nutr. PUCCAMP, Campinas, v. 3, n. 1, p. 21-41, jan./ jun. 1990.

\section{TURRA, M. Estudo da variação quantitativa de Nitratos e Nitritos} adicionados nos embutidos coloniais. 1998. Disponívelem: <http:// www.crmvsc.org.br/.../stories/ac/ac_graf_02.jpg>.Acesso em: 8 ago. 2008.

UFRGS (Universidade Federal do Rio Grande do Sul). Emprego de conservantes em alimentos. [s. d.] Disponível em: <http://www.ufrgs.br/ Alimentus/ped/seminarios/conservantes.doc>. Acesso em: 19 ago. 2008.

XIMENES, M. I. N.; RODRIGUES, G. M.; MARQUES, S. R. M. N. Teor Residual de Nitratos e Nitritos em produtos Cárneos Curados Comercializados no Distrito Federal. Revista de Saúde Pública do Distrito Federal, v. 9, n. 2, Abr/ Jun, 1998.

Title: InVestigation of Nitrite LeVel in Tuscan SAUSAges Commercialized in THE REGION OF FRANCA-SP

\section{Abstract}

The nitrite and nitrate salts in excess are harmful to health. This work aimed at evaluating the quality of the Tuscan sausages from several producers, commercialized in the region of Franca-SP, Brazil, through the analytic quantitative method of spectrophotometry. In parallel, an evaluation of the level of knowledge of the region's producers about the risks of the abusive use 
of the additive was done. The nitrite levels were analyzed in six samples of Tuscan sausage, numerically classified as: I, II, II, IV, V and VI, collected in different supermarkets. The method was based on the nitrite reaction with sulphanilic acid and -naphthol with formation of a colored compound. It was verified that the samples I, II and III presented a higher nitrite concentration than the one allowed by legislation $(150 \mathrm{mg} / \mathrm{kg})$. The questionnaire applied to three of the six producers, revealed that two of them did not know the legislation, did not do nitrite concentration analysis and only one declared that he did not know the harm that this additive could cause if indiscriminately used. The results showed that $50 \%$ of the samples were in disagreement with the legislation, thus, preventive measures must be taken such as quality control for industries and health monitoring of the food involved.

KEYWORDs: Nitrite; Sausage; Additives; Meat products; Legislation. 